paracme of Sonninine; during the second, the predominance of Parkinsonire.

The paper contains a hemeral timetable of the Eojurassic Period and part of the Neojurassic, a genealogical table of Ammonite development during the same and a previous portion of time, notes on certain generic names, and a list of the Ammonite genera referred to.

\title{
COREFSPONDEINCE.
}

\section{A MECHANICAL THEORY OF THE DIVINING-ROD.}

The review in Nature (1897, pp. 568, 569) of a publication relating to the "divining-rod," recalls to my mind a purely mechanical theory of that rod, which was given me years ago by a friend.

This theory has been repeatedly tested by me and shown to be correct in the presence of my classes. The process is exceedingly simple. Take any forked twig of a reasonably tough fibre in the clenched hands with the palms upward. The ends of the limbs forming the twig fork should enter the closed fists on the exterior side of each fist, i.e. on the two sides of the clenched hands furthest from each other.

When a twig is grasped in this position it will remain stationary if held loosely, or with only a moderately firm grasp; but the moment the grasp is tightened, the pressure on the branches will force the end of the twig to bend downwards. The harder the grip the more it must curve.

The curvature of the twig is mechanically caused by the pressure of the hands forcing the limbs to assume a bent and twisted position ; or the force that causes the forked limb to turn downwards is furnished by muscles of the hands, and not from any other cause.

The whole secret of the "divining-rod" seems to reside in its position in the hauds of the operator, and in his voluntarily or involuntarily increasing the closeness of his grasp on the two ends of the branches forming the fork.

If the above conditions are fulfilled the twig will always bend downwards-water or no water, mineral or no mineral; anyone can be an operator, and any material can be used for the instrument, provided the limbs forming the fork are sufficiently tough and flexible.

It can be easily understood how an ignorant operator may deceive himself, and be perfectly honest in supposing that some occult force, and not his hands, causes the fork to curve downwards.

M. E. Wadsworth.

Michigan College of Mines, Houghton, Michigan. 